\title{
ANGIOTENSIN CONVERTING ENZYME INHIBITION ACTIVITY OF DAIDZEIN
}

\author{
Avijit Choudhury*, Dr. K. Vasantkumar Pai
}

Department of PG Studies and Research in Industrial Chemistry, Kuvempu University, Shankaraghatta, Karnataka, India

\begin{abstract}
:
Daidzein produces antihypertensive and beneficial cardiovascular effects, although the mechanisms for these effects are not known. We examined whether genistein inhibits the in vivo responses to angiotensin I or enhances the responses to bradykinin in anaesthetized rats as a result of angiotensin-converting enzyme inhibition. We have also studied the in vitro effects produced by genistein on the angiotensin-converting enzyme activity. We measured the changes in systemic arterial pressure induced by angiotensin I in doses of 0.05 to $10 \mu \mathrm{g} / \mathrm{kg}$, by angiotensin II in doses of 0.025 to $5 \mu \mathrm{g} / \mathrm{kg}$, and to bradykinin in doses of 0.03 to $10 \mu \mathrm{g} / \mathrm{kg}$ in anaesthetized rats pretreated with vehicle (controls), or a single i.v. dose of daidzein $25 \mathrm{mg} / \mathrm{kg}$, or daily daidzein 25 $\mathrm{mg} / \mathrm{kg}$ i.v for two days, or a single i.v. dose of enalapril $2 \mathrm{mg} / \mathrm{kg}$. Plasma angiotensin-converting enzyme activity was determined in controls and daidzein-treated rats using a fluorometric method. The effects of genistein $(3-300 \mu \mathrm{mol} / \mathrm{l})$ on in vitro angiotensin-converting enzyme activity were assessed by adding daidzein to plasma samples and measuring angiotensinconverting enzyme activity. We found significant lower angiotensin-converting enzyme activity in plasma samples from rats pretreated with daidzein compared with those found in the control group $(84.23 \pm 7.4$ his-leu $\mathrm{nmol} / \mathrm{min} / \mathrm{ml}$ and $100.45 \pm 9.2 \mathrm{his}$ leu $\mathrm{nmol} / \mathrm{min} / \mathrm{ml}$, respectively; $\mathrm{P}=0.01$ ). The incubation of daidzein with plasma samples showed that daidzein decreased the angiotensin-converting enzyme activity in plasma in a concentration-dependent manner $(\mathrm{P}=0.01)$. These findings indicate that daidzein inhibits the angiotensin-converting enzyme in vivo and in vitro and may explain, at least in part, the antihypertensive and beneficial vascular effects produced by daidzein.
\end{abstract}

Keyword: Angiotensin, Daidzein, Bradykinin, Arterial pressure.

\section{INTRODUCTION}

Daidzein is an important isoflavone that is commonly found in soya beans and their derivative foods and produces several biological effects including significant improvement in endothelial function that may lead to protective cardiovascular effects, as suggested by findings from both experimental and clinical studies $1,2,3,4,5)$. Some of the cardiovascular effects produced by this isoflavone include inhibition of platelet aggregation $^{6,7}$, arterial vasorelaxation by nitric oxide dependent mechanisms ${ }^{8}$, and enhanced vasodilatation in response to acetylcholine, as previously shown in aorta from spontaneously hypertensive rats.

In agreement with these findings, increased soya isoflavone intake has been associated with significant reductions in arterial pressure, both in animal studies 9,10 and in clinical trials ${ }^{11}$. Although mounting evidence indicates that daidzein produces antihypertensive and protective cardiovascular effects, the mechanisms underlying such beneficial effects are still poorly known.

Angiotensin converting enzyme (ACE), a peptidyl dipeptidase enzyme, is a main regulator of the reninangiotensin system, which controls numerous important functions of the cardiovascular system. Indeed, ACE is liable for the conversion of relatively in active ACE-I to the potent vasoconstrictor ACE-II, which is the major product of the activation of the renin-angiotensin system
12 and a main controller of plasma volume, blood pressure, and sympathetic nervous activity. Although ACE-II can be generated by other enzymatic pathways, it has been broadly acknowledged that agents with ACE inhibiting properties produce valuable pharmacological and clinical effects ${ }^{13}$.

It is known that the plant-derived estrogens daidzein and daidzein have beneficial effects on serum lipids ${ }^{14}$, however, no previous study has examined in this regard whether daidzein inhibits the vascular responses to ACE or increases the responses to bradykinin. Therefore the aim of the present study was to examine whether daidzein inhibits the in vivo responses to ACE-I or enhances the responses to bradykinin in anaesthetized rats as a result of ACE inhibition.

*For correspondence: Mr. Avijit Choudhury Dept. of PG Studies and Research In Industrial Chemistry, Kuvempu University Shankaraghatta - 571451, Karnataka, India E-mail:avijitcology@rediffmail.com Mob. No: +918866825880 Tel. No: +91 261-2911477 Fax. No: +91 261-2911478 
We have also studied the in vitro inhibitory effects produced by daidzein on the ACE activity. ACE inhibitors exert beneficial effects on both the heart and the kidney; its effects on cardiac parameters were measured as well to investigate variation in cardiac therapy response.

\section{MATERIALS AND METHODS}

\section{Animals and treatments}

Male healthy Wistar rats (9 weeks old, 150-165g) were obtained from animal centre of Pretox Research Centre, Sachin, Surat, Gujarat, India. The rats were housed in plastic cages under identical conditions (12/ 12 hours light /dark cycle), in environmentally controlled rooms $\left(22 \pm 3^{0} \mathrm{C}\right.$ temperature, $50 \pm 20 \%$ relative humidity), including free access to both food (standard rat chow) and tap water. Animal care and treatment were conducted in compliance with Committee for the Purpose of Control and Supervision on Experiments on Animals (CPCSEA) guidelines. The experimental protocol was approved by the institutional animal ethics committee (IAEC protocol no.PRC/AFC/2013/037) of Pretox Research Centre, Sachin, Surat, Gujarat, India

They were allowed for acclimation under climatecontrolled conditions for a week before use. We compared survival in all groups throughout the treatment. All animals were carefully monitored, and the number of dead rats was recorded every day.

The rats were divided into three experimental groups. A first group was assigned to assess the arterial pressure responses to ACE-I, ACE-II, and bradykinin after a single dose of daidzein. The rats received vehicle (200 $\mu \mathrm{l}$ of dimethyl sulfoxide) or daidzein $(25 \mathrm{mg} / \mathrm{kg})$ $(\mathrm{n}=5$ /group) via their femoral veins and then doseresponse curves to ACE-I, ACE-II, and bradykinin were evaluated immediately as described below. A second group was assigned to assess the arterial pressure responses against same peptides after double doses of daidzein. The rats ( $n=8 /$ group) were treated for two days with daily i.v. injections of vehicle $(200 \mu \mathrm{l}$ of dimethyl sulfoxide) or daidzein $(25 \mathrm{mg} / \mathrm{kg})$ via their femoral veins and then dose-response curves to ACE-I, ACE-II, and bradykinin were recorded 2 hours after the second dose of daidzein as described below. Finally, a third or last group was designed to evaluate the pressure responses against peptides after a single dose of enalapril, as a positive control of daidzein. The rats ( $n=5$ /group) received vehicle $(200 \mu \mathrm{l}$ of saline) or enalapril $(2 \mathrm{mg} / \mathrm{kg})$ via their femoral veins and then dose-response curves to ACE-I, ACE-II, and bradykinin were evaluated as described below.

The dose of daidzein was chosen with basis on a previous study daidzein ${ }^{15}$ showing significant inhibitory effects on plasma ACE activity. The dose of enalapril was based on previous study ${ }^{16}$. The control animals received the same volumes of vehicle $(200 \mu l)$ as compared with those infused in treated animals.

At the end of experiments of the second group, blood samples were collected from rats treated with two doses of daidzein (or vehicle) to evaluate ACE activity.

\section{Preparation of animal for vascular responses}

On the day of surgery rats were anesthetized with ketamine injection $(40 \mathrm{mg} / \mathrm{kg}$, i.p.) and the trachea was cannulated carefully with a help of polyethylene tube (PE200) ${ }^{17}$. A polyethylene catheter (PE50) was surgically inserted into the left carotid and the systemic blood pressure was recorded using a data acquisition system (Power Lab Systems, ADinstrument) connected to a computer. For i.v injection of drugs another polyethylene catheter (PE50) was canulated into the right femoral vein rats. The absence of somatic motor reflexes in response to tail pitching or blinking in response to a low pressure corneal stimulation indicated deep anesthesia and analgesia. At least $15 \mathrm{~min}$ of stabilization was allowed before drug infusions.

\section{Preparation of drug and solution}

All drugs and reagents used were purchased from Sigma Chemical Co. (USA). Standard daidzein was a kind gift from Sahajanand Medical Technologies Pvt Ltd, Surat, India. Daidzein was dissolved in dimethyl sulfoxide. ACE-I, ACE-II, and bradykinin were dissolved in saline solution immediately before use.

\section{Dose response curves to ACE-I, ACE-II, and bradykinin}

All drugs were dissolved in saline and were given in a $100 \mu \mathrm{l}$ intravenous bolus. After baseline assessment of mean arterial pressure and heart rate for $25 \mathrm{~min}$, all rats received saline followed by ACE-I in doses of 0.05, 0.1, $0.5,1,5$, and $10 \mu \mathrm{g} / \mathrm{kg}$, followed by ACE-II in doses of $0.025,0.05,0.1,0.5,1$, and $5 \mu \mathrm{g} / \mathrm{kg}$, and then bradykinin in doses of $0.03,0.1,0.5,1,5$, and $10 \mu \mathrm{g} / \mathrm{kg}$. These doses were chosen with basis on previous studies 18 and in pilot studies. The changes in mean arterial pressure were calculated as the difference between the baseline value and those recorded at the highest values of mean arterial pressure after each dose of ACE-I or ACE-II, and as the difference between the baseline value and those recorded at the lowest values of mean arterial pressure after each dose of bradykinin. Each dose of drug was given when the mean arterial pressure had returned to baseline after the previous injection (usually 3-6 min) and real time mean arterial pressure recordings were carried out throughout the experiments.

\section{Effects of daidzein on plasma angiotensin-converting enzyme activity}

Plasma ACE activity of daidzein was assessed using a fluorometric method that measures the hydrolysis of the synthetic substrate hippuryl-His-Leu, as previously described ${ }^{19}$. Briefly, $5 \mu \mathrm{l}$ of plasma samples were incubated with $245 \mu \mathrm{l}$ of assay solution containing 5 $\mathrm{mM}$ hippuryl-His-Leu in $0.4 \mathrm{M}$ sodium borate buffer,

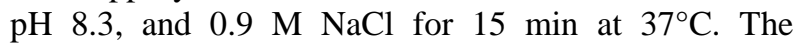
reaction was stopped by adding $600 \mu \mathrm{l}$ of $0.34 \mathrm{M}$ $\mathrm{NaOH}$. The product of this hydrolysis (His-Leu) was measured fluorometrically (365 nm excitation and 495 $\mathrm{nm}$ emission) after the addition of $50 \mu \mathrm{l}$ of ophthalaldehyde $(20 \mathrm{mg} / \mathrm{ml}$ in methanol), which was followed $10 \mathrm{~min}$ later by the addition of $100 \mu \mathrm{l}$ of $3 \mathrm{M}$ $\mathrm{HCl}$, and centrifugation at $800 \times \mathrm{g}$ for $5 \mathrm{~min}$. A standard curve was obtained with His-Leu $(0.1-30 \mu \mathrm{M})$, which produced a linear relationship of relative fluorescence and His-Leu concentrations (data not shown) ${ }^{20}$. 
Enalapril (Sigma Chemical Co., USA) $0.1 \mathrm{mM}$ was used as a positive control for this assay.

Effects of daidzein on in vitro angiotensinconverting enzyme activity

To examine the effects of daidzein on in vitro angiotensin converting enzyme activity, we added daidzein (from 3 to $300 \mu \mathrm{mol} / \mathrm{l}$ ) to plasma samples from rats and measured plasma angiotensin-converting enzyme activity as described above. These concentrations were based on previous studies showing that such concentrations inhibit angiotensin converting enzyme activity in rat aortic endothelial cells ${ }^{21}$. In addition, the concentrations range studied here contain the plasma daidzein levels measured in clinical and experimental studies 22,23 .

\section{Drugs and solutions}

All drugs and reagents used were purchased from Sigma Chemical Co. (USA). Daidzein was dissolved in dimethyl sulfoxide. ACE-I, ACE-II, and bradykinin were dissolved in saline solution immediately before use.

\section{STATISTICAL ANALYSIS}

The results are expressed as means \pm standard deviation. Comparisons of hemodynamic data between the groups were calculated by two-way analysis of variance (ANOVA) followed by Bonferroni post test. The between groups differences in plasma ACE activities were assessed by unpaired Student's ' $t$ ' test. One way analysis of variance followed by the Dunnet's test was used to analyze in vitro effects produced by the different concentrations of daidzein. A probability value $<0.05$ was considered significant.

\section{RESULTS}

We found no significant differences in body weight, mean arterial pressure, and heart rate responses among the groups of rats studied here (all $\mathrm{P}>0.05$, data not shown). Table 1 shows these parameters in rats treated with vehicle (controls) or daidzein for two days.

Table 1 Body weight (BW), mean arterial pressure (MAP) and heart rate (HR) in anesthetized rats treated with vehicle (Control) or Daidzein.

\begin{tabular}{|c|l|c|c|c|}
\hline Sr. No & \multicolumn{1}{|c|}{ Parameters } & Control (vehicle) & $\begin{array}{c}\text { Daidzein } \\
\mathbf{2 5 ~} \mathbf{~ m g} / \mathbf{k g}\end{array}$ & $\boldsymbol{P}$ value \\
\hline 1 & Body weight & $254 \pm 8.5$ & $249 \pm 9.2$ & $N S$ \\
\hline 2 & Mean arterial pressure & $100 \pm 5.8$ & $103 \pm 4.5$ & $N S$ \\
\hline 3 & Heart rate & $360 \pm 12.2$ & $392 \pm 11.2$ & $N S$ \\
\hline
\end{tabular}

\subsubsection{Effects of daidzein on vascular responses to angiotensin I, angiotensin II, and bradykinin}

To assess the outcomes of daidzein on ACE activity in vivo, we measured the changes in systemic arterial pressure induced by increasing doses of ACE-I, ACE-II, and bradykinin in anesthetized rats pretreated with vehicle, or after a single dose of daidzein, or after two doses of daidzein. Figure no. 1 shows the changes in systemic arterial pressure induced by ACE-I in doses of 0.05 to $10 \mu \mathrm{g} / \mathrm{kg}$ (panels $\mathrm{A}$ and D) and by ACE-II in doses of 0.025 t o $5 \mu \mathrm{g} / \mathrm{kg}$ (panels B and E), respectively. While the pretreatment with daidzein significantly reduced the hypertensive responses induced by ACE-I in doses of 1,3 , and $10 \mu \mathrm{g} / \mathrm{kg}$ (Figure no. $1 \mathrm{~A}$; $\mathrm{P}<0.05$ ), this drug produced no significant effects on the hypertensive responses induced by ACE-II (Figure no. $1 \mathrm{~B}$ and $\mathrm{E} ; \mathrm{P}>0.05)$. In addition, the pretreatment with Daidzein produces antihypertensive and beneficial cardiovascular effects, although the mechanisms for these effects are not known. We examined whether genistein inhibits the in vivo responses to angiotensin I or enhances the responses to bradykinin in anaesthetized rats as a result of angiotensin-converting enzyme inhibition. We have also studied the in vitro effects produced by genistein on the angiotensin-converting enzyme activity. We measured the changes in systemic arterial pressure induced by angiotensin $\mathrm{I}$ in doses of 0.05 to $10 \mu \mathrm{g} / \mathrm{kg}$, by angiotensin II in doses of 0.025 to 5 $\mu \mathrm{g} / \mathrm{kg}$, and to bradykinin in doses of 0.03 to $10 \mu \mathrm{g} / \mathrm{kg}$ in anaesthetized rats pretreated with vehicle (controls), or a single i.v. dose of daidzein $25 \mathrm{mg} / \mathrm{kg}$, or daily daidzein $25 \mathrm{mg} / \mathrm{kg}$ i.v for two days, or a single i.v. dose of enalapril $2 \mathrm{mg} / \mathrm{kg}$. Plasma angiotensin-converting enzyme activity was determined in controls and daidzein-treated rats using a fluorometric method. The effects of genistein $(3-300 \mu \mathrm{mol} / \mathrm{l})$ on in vitro angiotensin-converting enzyme activity were assessed by adding daidzein to plasma samples and measuring angiotensin-converting enzyme activity. We found significant lower angiotensin-converting enzyme activity in plasma samples from rats pretreated with daidzein compared with those found in the control group $(84.23 \pm 7.4$ his-leu $\mathrm{nmol} / \mathrm{min} / \mathrm{ml}$ and $100.45 \pm 9.2$ his-leu $\mathrm{nmol} / \mathrm{min} / \mathrm{ml}$, respectively; $\mathrm{P}=0.01)$. The incubation of daidzein with plasma samples showed that daidzein decreased the angiotensin-converting enzyme activity in plasma in a concentration-dependent manner $(\mathrm{P}=0.01)$. These findings indicate that daidzein inhibits the angiotensin-converting enzyme in vivo and in vitro and may explain, at least in part, the antihypertensive and beneficial vascular effects produced by daidzein.

daidzein significantly increased the hypotensive responses induced by bradykinin in doses of $0.3,1,5$, and $10 \mu \mathrm{g} / \mathrm{kg}$ (Figure no. $1 \mathrm{C}$ and $\mathrm{F} ; \mathrm{P}<0.05$ ). As a positive control, animals that received a single dose of enalapril (2 $\mathrm{mg} / \mathrm{kg})$ showed significantly lower 
hypertensive responses to angiotensin I (Figure no. 1G; $\mathrm{P}>0.05$ ), increased hypotensive responses to bradykinin (Figure no. $1 \mathrm{H} ; \mathrm{P}>0.05$ ), and no significant changes in the hypertensive responses induced by angiotensin II (Figure no. 1I; P>0.05).

\subsubsection{Daidzein inhibits in vitro angiotensin-} converting enzyme activity

We found significant lower angiotensin-converting enzyme activity in plasma samples from rats pretreated with daidzein compared with those found in plasma samples from rats in the Control group $(84.23 \pm 7.4$ hisleu $\mathrm{nmol} / \mathrm{min} / \mathrm{ml}$ and $100.45 \pm 9.2$ his-leu $\mathrm{nmol} / \mathrm{min} / \mathrm{ml}$, respectively; $\mathrm{P}=0.01$; Figure no. $2 \mathrm{~A}$ ). In addition, the incubation of daidzein $(10$ to $300 \mu \mathrm{M})$ with a pool of plasma samples from rats showed that daidzein decreased the angiotensin converting enzyme activity in plasma in a concentration-dependent manner $(\mathrm{Pb}<0.01$; Figure no. 2B).

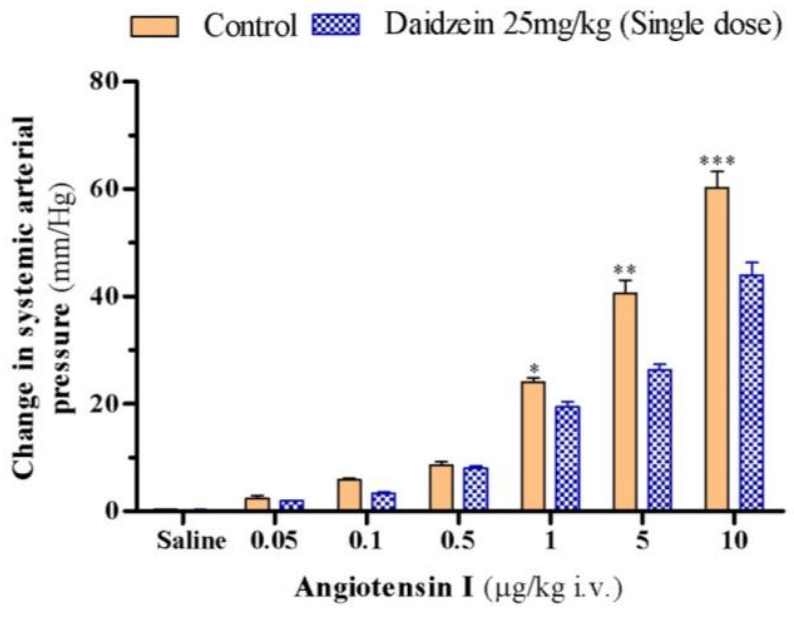

Figure 1 A

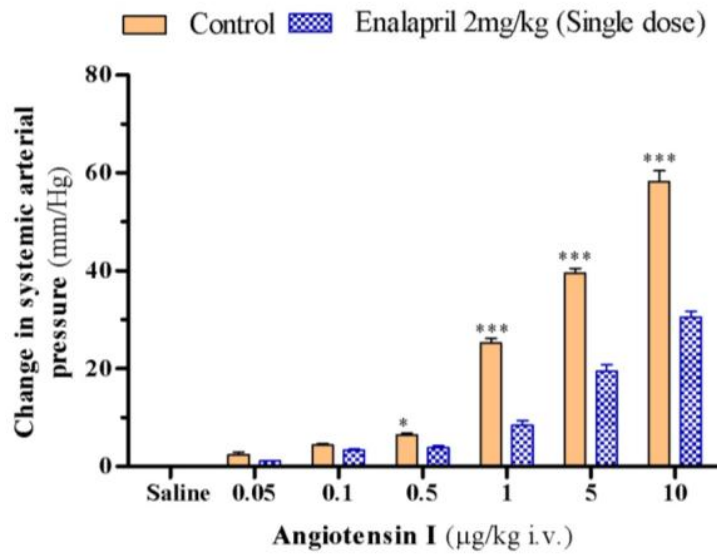

Figure 1 C

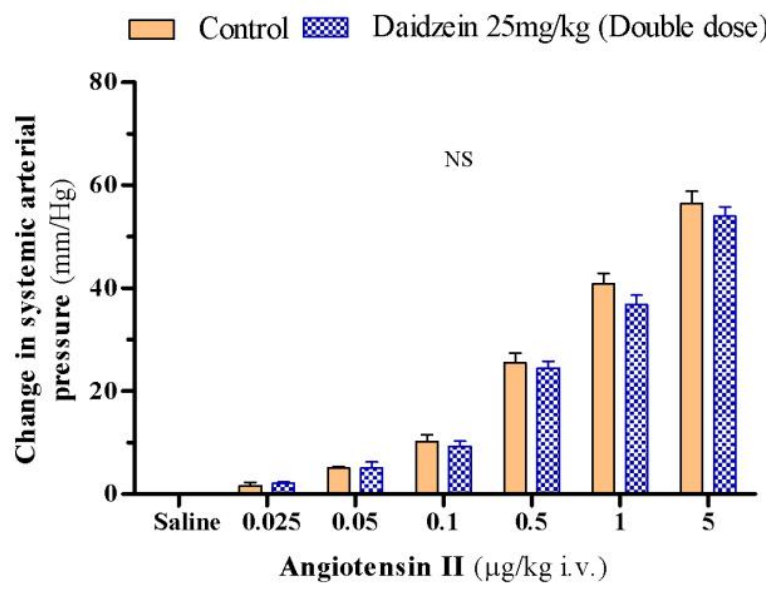

Figure 1 E

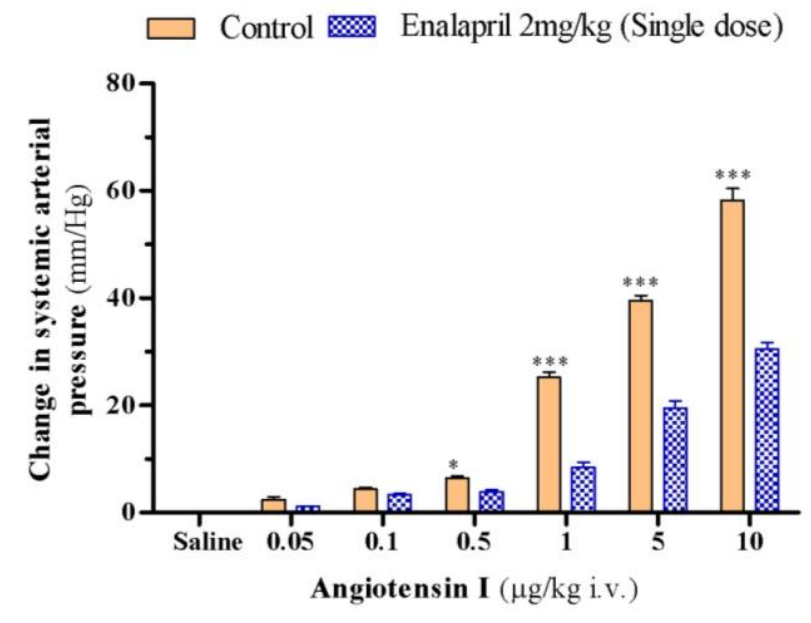

Figure1 B

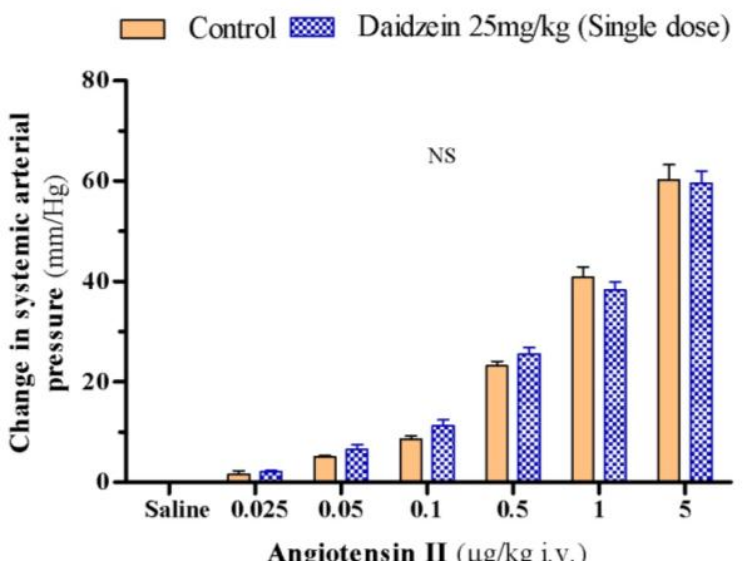

Figure 1 D

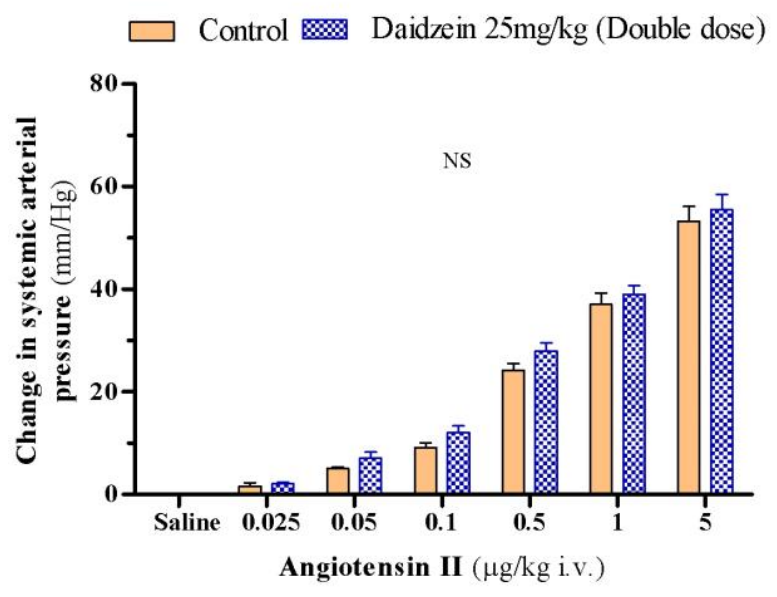

Figure 1 F 


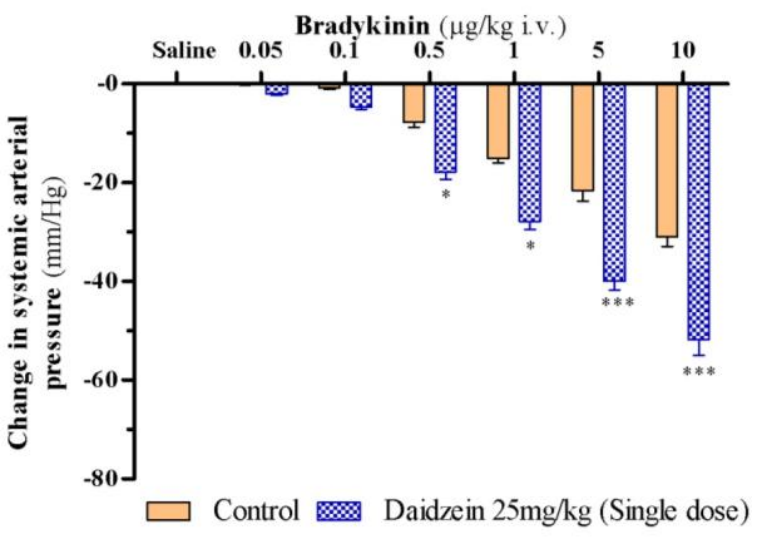

Figure 1 G

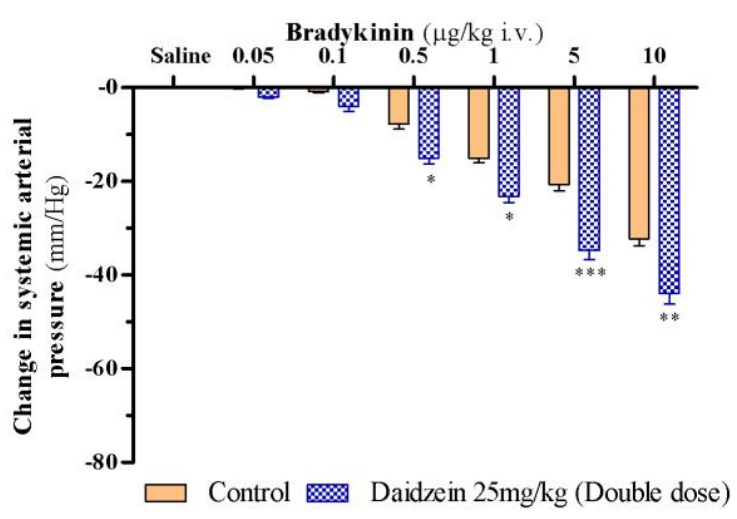

Figure $1 \mathrm{H}$

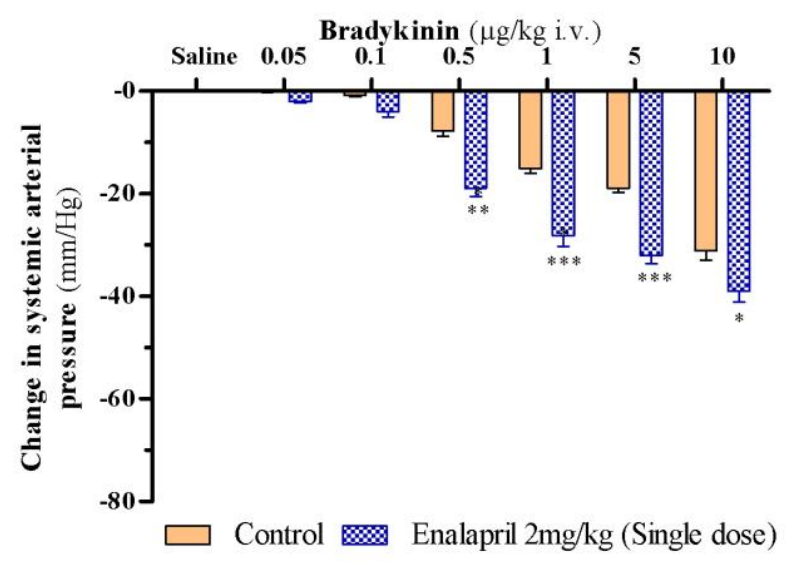

Figure 1 I

Figure no. 1. Change in systemic arterial blood pressure induced by the intravenous injections of saline and angiotensin $\mathrm{I}$ in doses of $0.03,0.1,0.3,1,3$, and 10 $\mu \mathrm{g} / \mathrm{kg}$, followed by angiotensin II in doses of $0.01,0.03$, $0.1,0.3,1$, and $3 \mu \mathrm{g} / \mathrm{kg}$, and then by bradykinin in doses of $0.03,0.1,0.3,1,3$, and $10 \mu \mathrm{g} / \mathrm{kg}$ in anesthetized animals treated with vehicle-control, or a single dose of daidzein (panels A, B and C), or two doses of daidzein (panels D, E and F) or single dose of captopril (panels G, $\mathrm{H}$ and I). Data are shown as mean \pm S.E.M; $\mathrm{n}=4$ per group in panels $\mathrm{A}, \mathrm{B}$, and $\mathrm{C} ; \mathrm{n}=8$ per group in panels $\mathrm{D}, \mathrm{E}$, and $\mathrm{F}$; and $\mathrm{n}=4$ per group in panels $\mathrm{G}, \mathrm{H}$, and $\mathrm{I}$. $* \mathrm{P}<0.05$, $* * \mathrm{P}<0.01$, $* * * \mathrm{P}<0.001$ versus the respective Control group. N.S. =non significant differences versus the respective Control group.

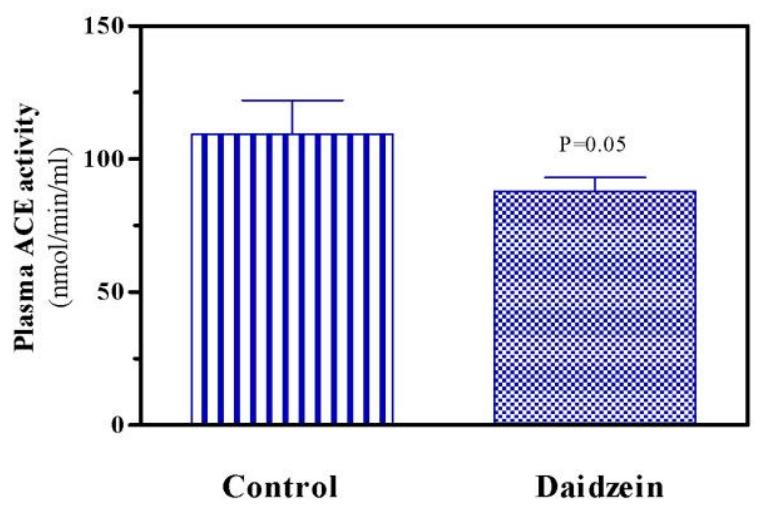

Figure 2
Figure no. 2. Panel A shows plasma angiotensin converting enzyme (ACE) activity in vehicle (Control) or after treatment with daidzein for two days. Angiotensin converting enzyme activity was assessed using a fluorometric method with the use of Hippuryl- His-Leu as substrate. Panel B shows daidzein induced inhibition of angiotensin converting enzyme (ACE) activity in vitro. A pool of plasma samples from rats was treated with captopril $0.1 \mathrm{mM}$, vehicle, or daidzein 3, 10, 30, 100 , and $300 \mu \mathrm{M}$. Data are shown as mean \pm S.E.M of at least three independent experiments performed in triplicate. $\mathrm{P}=0.01$ (Daidzein versus the Control group). $* * * \mathrm{P}<0.001$ versus the Control group.

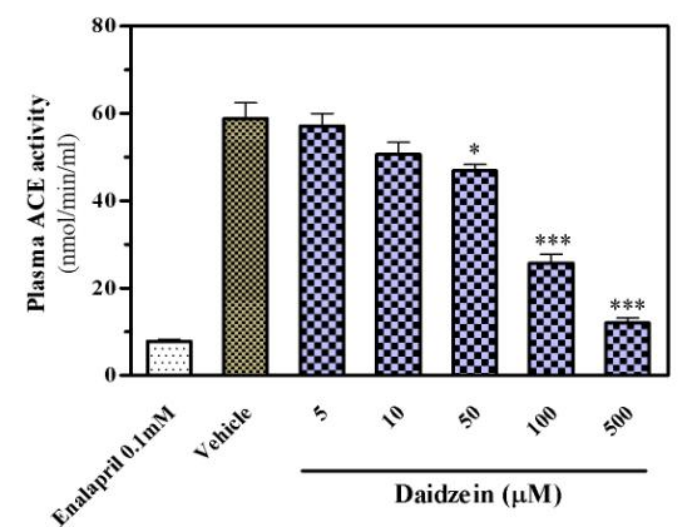

Figure 2 B 


\section{DISCUSSION AND CONCLUSION}

The major outcomes of this study were: (a) Daidzein pretreatment reduced the hypertensive responses persuaded by substance known as angiotensin I, and raised the hypotensive responses provoked by bradykinin without considerably modifying the responses to angiotensin II after two days of treatment; (b) these hemodynamic upshots were allied with significant decrease in activity of angiotensin converting enzyme in sample of plasma from rats pretreated with daidzein for two days compared with plasma of control group rats; (c) inhibitory action produced by daidzein in vivo on the angiotensin converting enzyme activity were corroborated with in vitro studies. Taken together, these data show daidzein produces relevant hemodynamic modifications and prove previous findings signifying that daidzein inhibits the ACE activity ${ }^{21}$.

Daidzein have various biological activities which is proved by several studies ${ }^{2}$. These actions comprise beneficial vascular alterations in humans ${ }^{24}$ and diminution in arterial blood pressure in animal models of hypertension. In fact, even though daidzein lowered the $\mathrm{BP}$ in spontaneously hypertensive rats ${ }^{2,3}$ and attenuated the hypertensive effects of dietary $\mathrm{NaCl}$ in hypertensive animals ${ }^{25}$, the precise mechanisms for these antihypertensive effects are poorly understood. Importantly, $\mathrm{Xu}$ et al. ${ }^{15}$ elegantly demonstrated for the first time that daidzein could inhibit the ACE activity in vitro as well as in plasma and tissues of rats via reduction of angiotensin-converting enzyme expression of the angiotensin converting enzyme ${ }^{15}$. On the other hand, no study has previously evaluated whether the inhibition of the angiotensin converting enzyme activity by daidzein could create relevant hemodynamic action in vivo, as we have shown in the present study.

The reduction in the responses to angiotensin I and the enhanced responses to bradykinin reported here, which were associated with lower ACE activity in vivo and in vitro, inflates earlier outcomes reported by $\mathrm{Xu}$ et al. ${ }^{15}$, The outcomes of this study show that, additionally to the inhibition of ACE expression, daidzein can inhibit angiotensin- converting enzyme activity in such a way that relevant hemodynamic modifications are produced. Actually, the angiotensin converting enzyme is a key enzyme regulating the rennin angiotensin aldosterone system (RAAS), and plays a vital role in the regulation of blood pressure and cardiovascular function.

The outcome of this study helps to explain how daidzein produced antihypertensive effects in earlier experiments $2,3,25$ using special models of hypertension. It would be interesting to examine the effects produced by daidzein on the angiotensin-converting enzyme expression and activity in different animal models of hypertension, especially in those with activated RAAS.

In conclusion, our findings show that daidzein reduced the hypertensive responses induced by angiotensin I, enhanced the hypotensive responses to bradykinin, and inhibited the angiotensin converting enzyme activity in plasma, both in vivo and in vitro. These findings indicate that daidzein inhibits the angiotensin converting enzyme and may explain, at least in part, the antihypertensive and beneficial vascular effects produced by daidzein

Conflict of interest: The author declare that there is no conflict of interest

\section{REFERENCES}

1. Nestel PJ, Yamashita T, Sasahara T, Pomeroy S, Dart A Komesaroff P, et al. Soy isoflavones improve systemic arterial compliance but not plasma lipids in menopausal and perimenopausal women. Arterioscler Thromb Vasc Biol. 1997; 17:3392-3398.

2. Si H, Liu D. Phytochemical genistein in the regulation of vascular function: new insights. Curr Med Chem. 2007; 14:2581-2589.

3. Vera R, Sanchez M, Galisteo M, Villar IC, Jimenez R, Zarzuelo A, et al. Chronic administration of genistein improves endothelial dysfunction in spontaneously hypertensive rats: involvement of eNOS, caveolin and calmodulin expression and NADPH oxidase activity. Clin Scim. 2007; 112: 183-191.

4. Washburn S, Burke G, Morgan T, Anthony M. Effect of soy protein supplementation on serum lipoproteins, blood pressure, and menopausal symptoms in perimenopausal women. Menopause. 1999; 6:7-13.

5. Hodgson J, Puddey I, Beilin L, Mori T, Burke V, Croft K, et al. Effects of isoflavonoids on blood pressure in subjects with high-normal ambulatory blood pressure levels: a randomized controlled trial. Am J Hypertens. 1999; 12:47-53.

6. Nakashima S, Koike T, Nozawa Y. Genistein, a protein tyrosine kinase inhibitor, inhibits thromboxane A2-mediated human platelet responses. Mol Pharmacol 1991; 39:475-480.

7. Akiyama $\mathrm{T}$, Ishida J, Nakagawa $\mathrm{S}$, Ogawara $\mathrm{H}$, Watanabe $\mathrm{S}$, Itoh $\mathrm{N}$, et al. Genistein, a specific inhibitor of tyrosine-specific protein kinase. J Biol Chem. 1987; 262:5592-5595.

8. Mishra SK, Abbot SE, Choudhury Z, Cheng M, Khatab N, Maycock NJ, et al. Endothelium-dependent relaxation of rat aorta and main pulmonary artery by the phytoestrogens genistein and daidzein. Cardiovasc Res. 2000; 46:539-546.

9. Anthony M, Clarkson T, Hughes CJ, Morgan T, Burke G. Soybean isoflavones improve cardiovascular risk factors without affecting the reproductive system of peripupertal rhesus monkeys. J Nutr. 1996; 126:43-50.

10. Figtree G, Griffiths H, Lu YQ, Webb C, MacLeod K, Collins $P$. Plant-derived estrogens relax coronary arteries in vitro by a calcium antagonist mechanism. J Am Coll Cardiol. 2000; 35:1977-1985.

11. Rivas M, Garay RP, Escanero JF, Cia JrP, Cia P, Alda JO. Soy milk lowers blood pressure in men and women with mild to moderate essential hypertension. J Nutr. 2002; 132:1900-1902.

12. Erdos EG, Skidgel RA. The angiotensin I-converting enzyme. Lab Invest J Tech Methods Pathol. 1987; 56:345-348.

13. Vane JR. The history of inhibitors of angiotensin converting enzyme. J Physiol Pharmacol. 1999; 50:489-498.

14. Anderson J, Johnstone B, Cook-Newell M. Meta-analysis of the effects of soy protein intake on serum lipids. N Eng J Med. 1995; 333:276-282.

15. Xu YY, Yang C, Li SN. Effects of genistein on angiotensinconverting enzyme in rats. Life Sci. 2006; 79:828-837.

16. Nossaman BD, Kaye AD, Kang B, Feng CJ, Kadowitz PJ. Effects of enalapril on responses to bradykinin in the hindquarters vascular bed of the rat. Peptides. 1997; 18:491494.

17. Tanus-Santos JE, Gordo WM, Francisco-DoPrado J, Sampaio RC, Moreno H. Endothelin-1 attenuates bradykinin-induced hypotension in rats. Eur J Pharmacol. 2000; 397:367-371.

18. Rohrdanz E, Ohler S, Tran-Thi QH, Kahl R. The phytoestrogen daidzein affects the antioxidant enzyme system of rat hepatoma H4IIE cells. J Nutr. 2002; 132(3):370-375.

19. Montenegro MF, Pessa LR, Tanus-Santos JE. Isoflavone genistein inhibits the angiotensin-converting enzyme and alters 
the vascular responses to angiotensin I and bradykinin. Eur $J$ Pharmacol. 2009; 607(3):173-177.

20. Neto-Neves EM, Montenegro MF, Dias-Junior CA, Spiller F, Kanashiro A, Tanus-Santos JE. Chronic treatment with quercetin does not inhibit angiotensin-converting enzyme in vivo or in vitro. Basic Clin Pharmacol Toxicol. 2010; 107(4):825-829.

21. Xu YY, Yang C, Li SN. Effects of genistein on angiotensinconverting enzyme in rats. Life Sci. 2006; 79:828-837.

22. Doerge DR, Churchwell MI, Chang HC, Newbold RR, Delclos KB. Placental transfer of the soy isoflavone genistein following dietary and gavage administration to Sprague Dawley rats. Reprod. Toxicol. 2001; 15:105-110.
23. Setchell KD, Zimmer-Nechemias L, Cai J, Heubi JE. Exposure of infants to phyto-oestrogens from soy-based infant formula. Lancet. 1997; 350:23-27.

24. Nestel PJ, Yamashita T, Sasahara T, Pomeroy S, Dart A, Komesaroff $\mathrm{P}$, et al. Soy isoflavones improve systemic arterial compliance but not plasma lipids in menopausal and perimenopausal women. Arterioscler Thromb Vasc Biol. 1997; 17:3392-3398

25. Cho TM, Peng N, Clark JT, Novak L, Roysommuti S, Prasain J, Wyss JM. Genistein attenuates the hypertensive effects of dietary $\mathrm{NaCl}$ in hypertensive male rats. Endocrinology. 2007; 148:5396-5402. 